\title{
Analytical Quality by Design Assisted HPLC Method for Quantification of Canagliflozin/ Metformin and Stability Studies
}

\author{
Sunitha Gurrala ${ }^{1,2, *}$, Shivaraj ${ }^{1}$, CVS Subrahmanyam², Panikumar Durga Anumolu², Gowthami Saraf $^{2}$ \\ ${ }^{1}$ Department of Chemistry, University College of Science, Osmania University, Hyderabad, INDIA. \\ ${ }^{2}$ Department of Pharmaceutical Analysis, Gokaraju Rangaraju College of Pharmacy, Osmania University, Hyderabad, Telangana, INDIA.
}

\begin{abstract}
Aim: Current work entails the analytical quality by design (AObD) based robust HPLC method for real-time analysis of canagliflozin and metformin. Different pKa values of two drugs made their chromatographic separation critical. Materials and Methods: The critical method parameters were systematically optimized using factorial experimental design (central composite design) and contours were generated as a function of significant variables when analyzed in the modeling software. The method operable design region that control the variation in response is obtained from contour plot and verified experimentally. Results: Effective chromatographic separation of title analytes was accomplished on SPOLAR $\mathrm{C}_{18}(250 \times 4.6 \mathrm{~mm}, 5 \mu)$ column at $25^{\circ} \mathrm{C}$ with mobile phase comprising of phosphate buffer, $\mathrm{pH} 6.0$ and acetonitrile $(55: 45 \% \mathrm{v} / \mathrm{v})$, pumped at a flow rate of $0.8 \mathrm{~mL} / \mathrm{min}$ by isocratic elution pattern and UV detection at $254 \mathrm{~nm}$. The linear model was established in the range of $50-300$ and $5-30$ and $\mu \mathrm{g} / \mathrm{mL}$ at retention times of 3.24 and 10.77 min for metformin and canagliflozin, respectively. Conclusion: Method obeyed all validation parameters of $\mathrm{ICH}$ Q2 (R1) guidelines and able to discriminate the Adduct generated upon drug degradation. The proposed method was pertinent for assay drugs and extended to quantify the drugs in prevalence of biological matrix.
\end{abstract}

Key words: AQbD, HPLC, Canagliflozin, Metformin, Degradation.

\section{INTRODUCTION}

Improved medication amenability for diabetic patients is usually accomplished through combinational therapy. Recently approved fixed-dose therapy combining canagliflozin and metformin in a single dosage form, indicated as an adjunct to diet and exercise to improve glycemic control in adults with type 2 diabetes mellitus. ${ }^{1}$ Canagliflozin chemically known as 2S,3R,4R,5S,6R)-2-(3-\{[5-(4-fluorophenyl) thiophen-2-yl] methyl -4 -methylphenyl)-6(hydroxymethyl) oxane-3,4,5-triol, is a novel and selective sodium-glucose transport protein (SGLT2) inhibitor, reduces reabsorption of filtered glucose and lowers the renal threshold for glucose, thereby increases urinary glucose excretion. Metformin chemically known as $N, N$-Dimethyl imido dicarbonimidic diamide, belongs to the class of organic biguanides. It decreases hepatic glucose production, decreases intestinal absorption of glucose and improves insulin sensitivity by increasing peripheral glucose uptake and utilization. The molecular structures are shown in Figure 1.

Several analytical methods such as spectrophotometric, HPLC, HPTLC and UPLC which have been reported for analysis of canagliflozin $^{2-6}$ and metformin ${ }^{7-10}$ in an entity or combination with other drugs. ${ }^{11-}$ ${ }^{14}$ Few UV, HPLC, stability-indicating and bioanalytical methods were also reported for estimation of metformin hydrochloride and canagliflozin, simultaneously. ${ }^{15-22}$ The reported conventional chromatographic methods were monotonous and concerned
Submission Date: 23-08-2019; Revision Date: 01-10-2019; Accepted Date: 31-10-2019

DOI: 10.5530/ijper.53.4s.167 Correspondence: Mrs. Sunitha Gurrala, Department of Pharmaceutical Analysis, Gokaraju Rangaraju College of pharmacy, Osmania University, Hyderabad-500090,Telangana INDIA.

Phone: +91 9966556830

E-mail: g.sunitha88@gmail. com

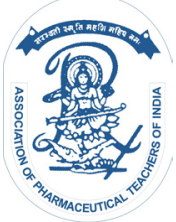

www.ijper.org 
with time consuming process of varying one factor at a time (OFAT), require large number of experimental runs and always yields a narrow robust method which has high risk of failure during transfer/ real-time usage. Analytical quality by design (AQbD) approach is one of the alternatives which dwindle the experimental time and cost for drug analysis. In recent times, pharmaceutical companies adopting QbD in analytics for troublefree compilation with FDA and ICH guidelines. AQbD explores scientific understanding of method variables and their interactions, finally provides a region for high robust and cost-effective approach. If an AQbD approach has been implemented in development stage, flexibility of an analytical method is granted without need of revalidation or regulatory review. ${ }^{23-26}$

Stability study through forced degradation of drug was used to predict the instability of drug and provide knowledge about possible degradation pathways / products of the active ingredients also helps to elucidate the structure of the degradants through characterization. ${ }^{27}$ Bioanalysis endeavors the accurate quantitative measure of active drug and/or its metabolite(s) in biological samples for the purpose of pharmacokinetic, toxicokinetic, bioequivalence and pharmacodynamic studies. ${ }^{28}$ The proposed chromatographic method is disparate to literature, here analytical method development through QbD approach has been followed. Present work is designed and developed for quantitative estimation of canagliflozin and metformin in API / pharmaceutical dosage form / biological fluids with an enactment of stability studies.

\section{MATERIALS AND METHODS}

\section{Materials}

The HPLC system (Shimadzu Corporation, Kyoto, Japan) connected to LC solution software, consisting of binary pump (LC-20AD), Rheodyne syringe loading manual sample injector $(20 \mu \mathrm{L})$, an UV detector (SPD$20 \mathrm{~A})$ and SPOLAR $\mathrm{C}_{18}(250 \mathrm{X} 4.6 \mathrm{~mm}, 5 \mu)$ column was used for the LC separation. The mobile phase was filtered through Millipore $(0.45 \mu \mathrm{m})$ glass filter assembly attached with a vacuum pump, sonicated with Ultra-Sonicator (RK 106, Spincotech) and pH of the solutions was measured with digital $\mathrm{pH}$ meter (LI- 120, Elico). Canagliflozin and metformin hydrochloride were obtained as gift samples from Dr. Reddys Laboratories, Hyderabad, India. Marketed formulation (INVOKAMET) with label claim $50 \mathrm{mg}$ of canagliflozin and $500 \mathrm{mg}$ of metformin per tablet was procured from local pharmacy. Ortho phosphoric acid, hydrochloric acid, potassium dihydrogen phosphate and acetonitrile (HPLC grade) were purchased from Merck, Mumbai, India. Series of phosphate buffer solutions ( $\mathrm{pH}$ 3-7) were prepared as per Indian Pharmacopeia. Sigma tech 3.1.1 software (Swarooptech Pvt. Ltd. Hyderabad) was employed for designing of LC experiments and response-modelling to generate design space for optimized robust analytical method.

\section{Preparation of mobile phase}

Potassium di hydrogen ortho-phosphate buffer, $\mathrm{pH}$ 6.0 and acetonitrile were mixed $(55: 45 \% \mathrm{v} / \mathrm{v})$ and filtered through $0.45 \mu \mathrm{m}$ membrane filter and sonicated to degas. Premixed mobile phase solution was used as diluent during the study.

\section{Binary standard solution}

In order to prepare binary standard solution, canagliflozin working standard of $10 \mathrm{mg}$ and metformin working standard of $100 \mathrm{mg}$ were weighed, decamped into $10 \mathrm{~mL}$ volumetric flask and dissolved in diluent by sonication. Volume was contrived up to the mark with diluent solution and the flask was shaken well (solutionA). Further $0.1 \mathrm{~mL}$ of this solution was diluted to 10 $\mathrm{mL}$ with diluent so as get binary working standard solution concentration of $10 \mu \mathrm{g} / \mathrm{mL}$ and $100 \mu \mathrm{g} / \mathrm{mL}$ for canagliflozin and metformin, respectively.

\section{Chromatographic conditions}

Chromatographic method development for simultaneous analysis of canagliflozin and metformin was done via $A Q b D$ approach. Initial chromatographic conditions were screened for type of column (ODS $\mathrm{C}_{18}$ or $\mathrm{C}_{8}$ ) and type of organic modifier (methanol or acetonitrile). Three variables (flow rate, $\mathrm{pH}$ of aqueous phase and $\%$ organic mobile phase) were selected for optimization where number of theoretical plates $(\mathrm{N})$ in experimental design was set aside as controlling response. Systematic chromatographic experimentation was performed using design of experiment tool of sigma tech software 3.1.1, which offer an effective and competent approach for studying all critical parameters at the same time to determine the effect of one factor in presence of others. Central composite design was utilized to determine the significant variables and optimize the chromatographic conditions with the lowest number of runs. The chromatographic trials suggested by the system were performed using Shimadzu HPLC system with SPOLAR $\mathrm{C}_{18}(250 \mathrm{~mm} \times 4.6 \mathrm{~mm} \times 5 \mu)$ column at UV detection wavelength $254 \mathrm{~nm}$.

\section{Method validation}

\section{System suitability test}


The efficiency of the method was monitored by applying system suitability test to chromatograms obtained through HPLC injection of standard blend solution for six times. ${ }^{29}$ System suitability parameters include theoretical plates, tailing factor, retention time and relative standard deviation (analyte peak area) for six consecutive injections were measured.

\section{Linearity and range}

Aliquots of about $0.5,1,1.5,2,2.5,3 \mathrm{~mL}$ were taken from mixed standard stock solution (solution-A) concurrently transferred into different volumetric flasks of $10 \mathrm{~mL}$ capacity. These solutions were diluted up to the mark with diluent such that the final concentration of metformin and canagliflozin in the range of 50-300 $\mu \mathrm{g} /$ $\mathrm{mL}$ and $5-30 \mu \mathrm{g} / \mathrm{mL}$ respectively was obtained. Injection volume of about $20 \mu \mathrm{L}$ was injected at each concentration level and calibration curve was constructed by plotting the peak area against the concentration of drug. Limit of detection (LOD) and limit of quantification (LOQ) were premeditated from the linear regression analysis data.

\section{Specificity}

The specificity study was performed to demonstrate the effective separation of title analyte peaks from placebo, biological matrix and all related degradation peaks. The placebo solution consisted of all the excipients commonly used for manufacturing of dosage form. Drugs were exposed to different stress conditions in order to generate its degradants.

\section{Accuracy}

To evaluate the accuracy of the method, recovery studies at three levels were performed by standard addition method. Test solutions were spiked with working standard solution at $80 \%, 100 \%$ and $120 \%$ of the target concentration and analyzed by contemplated method. The samples were prepared in triplicate at each level and the $\%$ recovery of drug was calculated by measuring the peak area of chromatogram.

\section{Precision}

Mixed binary standard solution of canagliflozin $(20 \mu \mathrm{g} /$ $\mathrm{ml})$ and metformin $(200 \mu \mathrm{g} / \mathrm{ml})$ was prepared as per procedure mentioned and injected the same solution for six times to check the system precision. Method precision study was carried out by estimating corresponding responses of drug solutions prepared for six times for the concentration of canagliflozin $20 \mu \mathrm{g} / \mathrm{ml}$ and metformin $200 \mu \mathrm{g} / \mathrm{ml}$ when analyzed through proposed method. The retention time and area of the determinations were measured and \%RSD was calculated.

\section{Robustness verification}

In order to assess the robustness of the method, deliberate changes in method critical parameters were made within MODR. The variations in the parameters include $\mathrm{pH}( \pm 0.2)$, organic phase $( \pm 2 \%)$, flow rate $( \pm 0.1 \mathrm{ml} /$ min) of mobile phase and detector wavelength $( \pm 2$ $\mathrm{nm})$. The $\%$ RSD of retention time and theoretical plates of chromatogram obtained for every variation was premeditated.

\section{Application of contemplated method}

\section{Assay of marketed formulation}

Twenty tablets of marketed pharmaceutical formulation (INVOKAMET), each containing $50 \mathrm{mg}$ of canagliflozin and $500 \mathrm{mg}$ of metformin were taken and accurately weighed. The average weight $(762.28 \mathrm{mg}$ ) was determined and crushed in to fine powder. An accurately weighed quantity of powder $(152.45 \mathrm{mg})$ equivalent to $10 \mathrm{mg}$ of canagliflozin and $100 \mathrm{mg}$ of metformin was transferred to volumetric flask of $100 \mathrm{~mL}$ capacity and dissolved in mobile phase by sonication. The flask volume was made up to the mark with mobile phase and filtered the solution through Whatman filter paper (No. 41). The filtrate of $1 \mathrm{~mL}$ was diluted to $10 \mathrm{~mL}$ with mobile phase and analyzed with contemplated method. The amount of canagliflozin and metformin present in sample solution was determined.

\section{Stability testing}

Degradation of drug was achieved by situated the drugs under stress conditions as per ICH Q1A (R2) guideline. ${ }^{30}$ Each $5 \mathrm{~mL}$ of binary standard solution (solutionA) and $0.5 \mathrm{~N}$ hydrochloric acid solution were mixed and heated at $60^{\circ} \mathrm{C}$ for $60 \mathrm{~min}$. Anon solution was cooled and neutralized with $0.5 \mathrm{~N}$ sodium hydroxide solution. Similarly, alkali ( $0.5 \mathrm{~N}$ sodium hydroxide), neutral (water) and peroxide $\left(6 \% \mathrm{v} / \mathrm{v} \mathrm{H}_{2} \mathrm{O}_{2}\right)$ degradation studies were carried out. Photolytic and thermal degradation studies were carried out in the solid state by exposing a very thin layer of pure canagliflozin and metformin in a petri plate to UV-light $(365 \mathrm{~nm}$ and $254 \mathrm{~nm})$ and heat $\left(105^{\circ} \mathrm{C}\right)$ for $48 \mathrm{~h}$. Finally, all stressed samples were diluted with mobile phase, analyzed by contemplated HPLC method and chromatograms were recorded to assess the stability of drugs. Concurrent analysis of controlled sample was done along with stressed samples.

\section{Bioanalysis}


Collected whole human blood (drug free) into commercially available anticoagulant (EDTA) treated tubes (lavender tops) and subjected for centrifugation for $10 \mathrm{~min}$ at $2000 \mathrm{rpm}$ to remove cells. The resulting supernatant liquid (designated as plasma) of $1 \mathrm{~mL}$ was immediately transferred into a clean polypropylene tube using a Pasteur pipette. To this $1 \mathrm{~mL}$ of acetonitrile (precipitating agent) and $1 \mathrm{~mL}$ of binary standard solution (solutionA) was added, mixed well and volume was contrived upto $10 \mathrm{~mL}$ with mobile phase. This solution was centrifuged for $10 \mathrm{~min}$, collected the $0.1 \mathrm{~mL}$ supernatant solution, diluted to $10 \mathrm{~mL}$ with mobile phase and filtered. The filtrate of $20 \mu \mathrm{L}$ was injected into the HPLC system and analyzed with contemplated method.

\section{RESULTS AND DISCUSSION}

\section{Preliminary studies}

Authentication of drugs was confirmed by determination of melting point, UV absorption spectra $\left(\lambda_{\max }\right)$ and principal peaks in FT-IR. Results of these studies were compared with the reference values and found to be within the limit of acceptance. The individual methanolic standard solutions $(10 \mu \mathrm{g} / \mathrm{mL})$ of canagliflozin and metformin when analyzed in UV spectrophotometer ranging from $200 \mathrm{~nm}-400 \mathrm{~nm}$, showed iso-absorptive point at $254 \mathrm{~nm}$. Hence chromatographic peak integration was done at $254 \mathrm{~nm}$ in order to get maximum responses for both analytes.

\section{Screening experiments}

In HPLC, two key parameters influence selectivity such as the chemistry of stationary phase and organic modifiers in mobile phase. Scouting of stationary phase was performed using columns (ODS $\mathrm{C}_{18}$ and $\mathrm{C}_{8}$ ) with diverse chemistry. Bonded phase ODS $\mathrm{C}_{18}$ provides superior analyte elution with good peak shape, hence RP-HPLC technique with ODS $\mathrm{C}_{18}$ column was selected for analysis. Methanol and/or acetonitrile were chosen as organic modifiers for screening. Where acetonitrile showed selectivity and good separation of analytes within short run time than methanol. Hence acetonitrile was selected as organic modifier. Analyte peak identity was confirmed through retention time comparison.

\section{QbD assisted method development}

Analytical quality by design (AQbD) method development strategy is a logical and science-based approach where method requirements and critical controls are need to be identified/ defined in the early stage of method development. AQbD method design includes defining Analytical Target Profile (ATP), Critical Qual- ity Attributes (CQAs), identifying Critical Method Parameters (CMPs) with risk assessment and generation of Design Space (DS).

Analytical Target Profile (ATP) of the proposed method is liquid chromatographic separation of canagliflozin and metformin from each other as well as from their degradant peaks/ impurities and biological matrix.

Critical Quality Attributes (CQAs) are measurable attributes of the chromatogram that should be within an appropriate limit (or) range to ensure the desired quality of the method. For chromatographic methods, CQAs are resolution, number of theoretical plates, tailing and retention time of analytical peak etc. In the present study, number of theoretical plates $(\mathrm{N})$ which embodies the efficiency of separation was selected as CQA.

Critical Method Parameters (CMPs) are the factors whose variability has an impact on CQA, selected by sciencebased process called quality risk assessment. Different $\mathrm{pKa}$ values of two drugs recommends the optimization of desirable $\mathrm{pH}$ of mobile phase. Peak symmetry and stationary-mobile phase interactions will depend on flow rate. Retention factor ( $k^{\prime}$ ) value will be most readily modified by changing the $\%$ of organic mobile phase. Hence mobile phase flow rate, aqueous phase $\mathrm{pH}$ and organic mobile phase (\%) were selected as typical Chromatographic Method Parameters (CMPs), shown in Table 1 . These plays a crucial role in maintaining consistent retention of analytes, selectivity and reproducibility of a method. Risk on method performance is assessed by simultaneous evaluation of all method variables and their interactions.

In order to ascertain optimum chromatographic conditions, selected variables were screened using factorial experimental design $\left(2^{3}\right)$. Software designed experimental runs were performed with respect to three variables such as $\%$ organic phase (X1), flow rate (X2) and $\mathrm{pH}$ of aqueous mobile phase (X3) to acquire theoretical plate count for both analytes as method control responses. The Software suggested central composite experimental design (CCD) and their responses were depicted in Table 2.

\section{Statistical analysis}

Statistical analysis of experimental observations was performed to evaluate significant factors that affect the chromatographic response, given in Table 3. Polynomial equations for prediction of responses were obtained as follows.

$\mathrm{Y} 1=9733.3+(-1320.62) \mathrm{b}_{1}+(-1287.37) \mathrm{b}_{2}+(135.37)$ $\mathrm{b}_{12}+(-301.37) \mathrm{b}_{3}+(-483.62) \mathrm{b}_{13}+(-60.37) \mathrm{b}_{23}+$ $(-61.625) b_{123}$ 
$\mathrm{Y} 2=4155+(66.875) \mathrm{b}_{1}+(-655.875) \mathrm{b}_{2}+(-72.875)$ $\mathrm{b}_{12}+(-492.375) \mathrm{b}_{3}+(32.125) \mathrm{b}_{13}+(-178.875) \mathrm{b}_{23}+$ (47.875) $\mathrm{b}_{123}$

Statistical data analysis of canagliflozin exhibited X1 $(\%$ organic phase) as significant factor owing to highest SS ratio $(53.52 \%)$ at b1 combination. The negative sign of the b1 coefficient indicates the lower $\%$ organic mobile phase, increases the response $(\mathrm{N})$ of chromatographic system. Variable X2 (flow rate) is also an important factor $(\mathrm{SS}=38.36 \%)$ and assumed to be better response obtained at lower flow rates. Insignificant effect on response was observed with $\mathrm{X} 3$ ( $\mathrm{pH}$ of aqueous phase) and variable interactions.

The highest SS ratio $(59.9369 \%)$ was obtained at b2 combination i.e; $\mathrm{X} 2$ variable so that flow rate was the main variable for analysis of metformin. The negative sign of b2 coefficient indicates lower mobile phase flowrate on the column, increases the response (theoretical plates number). Aqueous mobile phase $\mathrm{pH}$ i.e. b3 ( $\mathrm{SS}=33.78 \%$ ) has negative coefficient, hence at the lower $\mathrm{pH}$ values theoretical plates number can be increased. Insignificant effect on response was observed with X1 (\% organic mobile phase) and variable interactions.

Further analysis was attempted for observing curvature effect at 95\% confidence levels. ANOVA indicated that the process model with $\mathrm{X} 1, \mathrm{X} 2, \mathrm{X} 3$ along with interactions is highly significant at 95\% Confidence level $(p<0.05)$. Since curvature effect is significant and says non-linear relationship between $\mathrm{Y}$ and $\mathrm{X}$. Hence obligatory to go for central composite design (CCD).

Design Space (DS) generally termed as method operable design region (MODR) obtained through simulation technique $(2 \mathrm{D} / 3 \mathrm{D})$ which can be used to find out the response for a given set of input variables. Data obtained from the statistical model experimentation was analyzed in the modeling software by contour plot (2D) method. Two-dimensional graphs (contours) were generated as a function of significant variables while third variable was held constant at a specified (optimum) level, illustrated in Figure 2. It was noted that design space for proposed analytical method was large to get high number of theoretical plates $(\mathrm{Y} 1=8000-13500, \mathrm{Y} 2=4000-7000)$ with respect to different levels of CMPs. Those levels were optimized using contour plots.

Figure $2 \mathrm{a}$ illustrates the $\%$ organic mobile phase has prominent effect on theoretical plate number of canagliflozin (Y1) and indicates organic modifier above +1 level (65\%) and below -1 level (45\%) decreases the response (Y1). Flow rate of mobile phase at any level $(-2$ to +2$)$ can produce maximum response. Hence $\%$ organic phase at lower level (-1) and flow rate at lowest level (-2) can be preferred which dwindle the cost of experiment.

Figure $2 \mathrm{~b}$ demonstrates that theoretical plate number for metformin (Y2) decreases with increase in flow rate and $\mathrm{pH}$ of aqueous mobile phase. Flow rate at lower level $(-2$ to +1$)$ can be preferred which may produce maximum response (Y2) and reduces the solvent consumption. Even though aqueous phase $\mathrm{pH}$ from -2 level to +1 level showed higher number of theoretical plates for metformin, the $\mathrm{pH}$ at +1 level is preferred in order to achieve analyte stability in mobile phase and to preserve lifetime of column. Hence mobile phase with $\mathrm{pH}$ 6.0 can be chosen.

\section{Optimized experimental conditions}

The robust HPLC parameters were optimized as mobile phase consisting of phosphate buffer, $\mathrm{pH} 6.0$ and acetonitrile $(55: 45 \% \mathrm{v} / \mathrm{v})$, pumped at a flow rate of $0.8 \mathrm{~mL} /$ min on SPOLAR C 18 ( $250 \times 4.6 \mathrm{~mm}, 5 \mu)$ column by isocratic elution pattern with injection volume of $20 \mu \mathrm{L}$ at $25^{\circ} \mathrm{C}$ column temperature. The detection was carried out at $254 \mathrm{~nm}$ and retention time were found to be and 3.24 and $10.77 \mathrm{~min}$ for metformin and canagliflozin, respectively.

\section{Method validation}

The verified method was validated according to $\mathrm{ICH}$ Q2 (R1) guidelines. A linear response was willful over the examined concentration range of $5-30 \mu \mathrm{g} / \mathrm{mL}$ and $50-300 \mu \mathrm{g} / \mathrm{mL}$ for canagliflozin and metformin, respectively. The chromatogram of linearity was demonstrated in Figure 3. Chromatograms of blank, placebo and biological matrix had dearth of peak at the retention time of title drugs indicated the specificity of method. The accuracy of the method was validated by recovery studies and was found to be significant under specification limits with afforded recovery 98.7- $100.4 \%$ and 98.3$100.3 \%$ of canagliflozin and metformin, respectively. The $\%$ RSD values for intra-day and inter-day study were less than 2.0, endorsed the good repeatability of proposed method. Predicted response of optimized method parameters in robust process (MODR of contour plot) was verified experimentally and the difference

\begin{tabular}{|c|c|c|c|}
\hline \multicolumn{4}{|c|}{ Table 1: Factors selected for QbD method. } \\
\hline Variables/ factors & Units & $\begin{array}{c}\text { Lower level } \\
(-1)\end{array}$ & $\begin{array}{c}\text { Upper level } \\
(+1)\end{array}$ \\
\hline $\begin{array}{c}\text { Organic mobile phase } \\
(\mathrm{X} 1)\end{array}$ & $\%$ & 45 & 65 \\
\hline Flow rate (X2) & $\begin{array}{c}\mathrm{mL} / \\
\mathrm{min}\end{array}$ & 0.6 & 1.0 \\
\hline $\begin{array}{c}\mathrm{pH} \text { of aqueous phase } \\
(\mathrm{X} 3)\end{array}$ & - & 4 & 6 \\
\hline
\end{tabular}




\begin{tabular}{|c|c|c|c|c|c|}
\hline \multirow{2}{*}{ Combination } & & & & \multicolumn{2}{c|}{ Theoretical plate number } \\
\hline & \%Organic phase & Flow rate & pH & \multicolumn{2}{c|}{ Metformin (Y2) } \\
\cline { 2 - 6 } & $\mathbf{X}_{1}$ & $\mathbf{X}_{2}$ & $\mathbf{X}_{3}$ & Canagliflozin (Y1) & 5327 \\
\hline $\mathrm{X}_{1}$ & 45 & 0.6 & 4 & 13313 & 5638 \\
\hline $\mathrm{X}_{2}$ & 65 & 0.6 & 4 & 9452 & 3899 \\
\hline $\mathrm{X}_{1} \mathrm{X}_{2}$ & 45 & 1 & 4 & 10765 & 3727 \\
\hline $\mathrm{X}_{3}$ & 65 & 1 & 4 & 6609 & 4016 \\
\hline $\mathrm{X}_{1} \mathrm{X}_{3}$ & 45 & 0.6 & 6 & 11499 & 4264 \\
\hline $\mathrm{X}_{2} \mathrm{X}_{3}$ & 65 & 0.6 & 6 & 9819 & 3113 \\
\hline $\mathrm{X}_{1} \mathrm{X}_{2} \mathrm{X}_{3}$ & 45 & 1 & 6 & 9439 & 3260 \\
\hline $\mathrm{Midpoint}$ & 65 & 1 & 6 & 6971 & 4882 \\
\hline $\mathrm{X}_{1}-2 \mathrm{~L}$ & 55 & 0.8 & 5 & 9795 & 4505 \\
\hline $\mathrm{X}_{1}+2 \mathrm{~L}$ & 35 & 0.8 & 5 & 2000 & 4736 \\
\hline $\mathrm{X}_{2}-2 \mathrm{~L}$ & 75 & 0.8 & 5 & 7128 & 5295 \\
\hline $\mathrm{X}_{2+} 2 \mathrm{~L}$ & 55 & 0.4 & 5 & 12441 & 3294 \\
\hline $\mathrm{X}_{3} 2 \mathrm{~L}$ & 55 & 1.2 & 5 & 8303 & 4695 \\
\hline $\mathrm{X}_{3}+2 \mathrm{~L}$ & 55 & 0.8 & 3 & 9616 & 3545 \\
\hline
\end{tabular}

CCD: Central composite design, L: Level

\begin{tabular}{|c|c|c|c|c|}
\hline \multirow{2}{*}{ Table 3: Statistical data analysis of factorial experimental design $\left(^{3}\right)}$. \\
\hline \multirow{2}{*}{ Combination } & \multicolumn{2}{|c|}{ Canagliflozin } & \multicolumn{2}{c|}{ Metformin } \\
\cline { 2 - 5 } & Coefficient & SS Ratio & Coefficient & SS Ratio \\
\hline$b_{0}$ & 9733.3 & -- & 4155.37 & -- \\
\hline$b_{1}$ & -1320.62 & $53.52 \%$ & 66.87 & $0.62 \%$ \\
\hline$b_{2}$ & -1287.37 & $38.36 \%$ & -655.87 & $59.93 \%$ \\
\hline$b_{12}$ & -135.37 & $0.42 \%$ & -72.87 & $0.74 \%$ \\
\hline$b_{3}$ & -301.37 & $2.10 \%$ & -492.37 & $33.78 \%$ \\
\hline$b_{13}$ & -483.62 & $5.41 \%$ & 32.12 & $0.14 \%$ \\
\hline$b_{23}$ & -60.37 & $0.08 \%$ & -178.87 & $4.45 \%$ \\
\hline$b_{123}$ & -61.62 & $0.08 \%$ & 47.87 & $0.32 \%$ \\
\hline
\end{tabular}

$* \mathrm{X}_{1}=\mathrm{b}_{1}=\%$ Organic mobile phase, $\mathrm{X}_{2}=\mathrm{b}_{2}=$ Flow rate, $\mathrm{X}_{3}=\mathrm{b}_{3}=\mathrm{pH}$ of aqueous phase

(percent residual) between the predicted and observed results was found within $\pm 8 \%$. Documenting this data will determine the degree of impact of planned / accidental changes on method. Results of system suitability test and validation were represented in Table 4.

\section{Application of method}

\section{Assay of marketed formulation}

The results obtained for assay of canagliflozin and metformin were compared with the corresponding labeled amounts and reported in Table 5. The chromatogram obtained for analysis of marketed formulation (Invokamet) has dearth of additional peaks, indicated no interference of the formulation excipients used in the tablet, depicted in Figure 4. The \% assay of canagliflozin and metformin found to be $98.02 \%$ and $100.1 \%$, respectively. These results were within the limits $98-102 \%$.

\section{Stability testing}

The chromatograms of samples subjected to various forced degradation conditions showed well-separated peaks of the analytes and degradation products at different retention times, depicted in Figure 5. However, in some conditions, chromatograms did not show separate peaks of the degradation products, rather a decrease in height and area of the analyte peak was observed. Summary of degradation studies was reported in Table 6 . It was observed that metformin is susceptible towards alkaline degradation more than any other applied stress conditions. Significant degradation of canagliflozin was observed upon exposure to base hydrolysis, photolytic 


\begin{tabular}{|c|c|c|c|}
\hline \multicolumn{2}{|c|}{ Parameter } & Results of Canagliflozin & Results of metformin \\
\hline \multirow{3}{*}{ Linearity } & Linearity range & $5-30 \mu \mathrm{g} / \mathrm{ml}$ & $50-300 \mu \mathrm{g} / \mathrm{ml}$ \\
\hline & Correlation co-efficient $\left(R^{2}\right)$ & 0.999 & 0.999 \\
\hline & Regression equation & $Y=4365 X-1184$ & $Y=5349 X-24204$ \\
\hline \multirow{2}{*}{ Sensitivity } & $\operatorname{LOD}(\mu g / m L)$ & 0.5 & 0.91 \\
\hline & $\operatorname{LOQ}(\mu g / m L)$ & 1.67 & 2.84 \\
\hline \multirow{2}{*}{$\begin{array}{c}\text { Precision } \\
\text { (\% RSD of peak } \\
\text { area) }\end{array}$} & Intra-day precision & 0.147 & 0.13 \\
\hline & Inter-day precision & 0.184 & 0.256 \\
\hline \multirow{3}{*}{$\begin{array}{l}\text { Accuracy } \\
\text { (\% RSD of } \\
\text { recovery) }\end{array}$} & $80 \%$ level & 0.172 & 0.238 \\
\hline & $100 \%$ level & 0.761 & 0.475 \\
\hline & $120 \%$ level & 0.528 & 0.416 \\
\hline \multirow{4}{*}{$\begin{array}{l}\text { Robustness } \\
\text { (\% RSD of peak } \\
\text { area) }\end{array}$} & Flow rate $( \pm 0.1 \mathrm{~mL} / \mathrm{min})$ & 1.22 & 1.17 \\
\hline & $\mathrm{pH}( \pm 0.2)$ & 0.821 & 0.965 \\
\hline & Organic phase $( \pm 1 \%)$ & 1.45 & 1.21 \\
\hline & Wavelength $( \pm 2 \mathrm{~nm})$ & 1.07 & 0.947 \\
\hline \multirow{9}{*}{ System suitability } & Retention time (min) & 10.77 & 3.24 \\
\hline & Peak area & 86060 & 1087270 \\
\hline & Theoretical plate number ${ }^{\mathbf{\Delta}}$ & 11073 & 4280 \\
\hline & Tailing factor & 1.2 & 1.3 \\
\hline & Stationary phase & \multicolumn{2}{|c|}{ SPOLAR C $_{18}(250 \times 4.6 \mathrm{~mm}, 5 \mu \mathrm{m})$} \\
\hline & Mobile phase* $^{*}$ & \multicolumn{2}{|c|}{ Acetonitrile: Phosphate buffer $\mathrm{pH} 6(45: 55 \mathrm{v} / \mathrm{v})$} \\
\hline & Flow rate* & \multicolumn{2}{|c|}{$0.8 \mathrm{~mL} / \mathrm{min}$} \\
\hline & Detector wavelength & \multicolumn{2}{|c|}{$254 \mathrm{~nm}$} \\
\hline & Resolution & \multicolumn{2}{|c|}{$25 \mathrm{~min}$} \\
\hline
\end{tabular}

*Optimized in experimental design, $\mathbf{\Delta}$ Response considered in experimental design, RSD- Relative standard deviation, $n=3$.

\begin{tabular}{|c|c|c|c|c|c|c|c|c|}
\hline \multirow[b]{2}{*}{ Formulation } & \multicolumn{4}{|c|}{ Canagliflozin } & \multicolumn{4}{|c|}{ Metformin } \\
\hline & $\begin{array}{c}\text { Label } \\
\text { claim } \\
(\mathrm{mg})\end{array}$ & $\begin{array}{c}\text { Amount found } \\
\text { (mg) } \\
\text { (A.M } \pm \text { SD) }\end{array}$ & $\begin{array}{c}\% \\
\text { Assay }\end{array}$ & \% RSD & $\begin{array}{l}\text { Label } \\
\text { claim } \\
(\mathrm{mg})\end{array}$ & $\begin{array}{c}\text { Amount } \\
\text { found(mg) } \\
\text { (A.M }(\mathrm{SD})\end{array}$ & $\%$ Assay & $\%$ RSD \\
\hline Invokamet & 50 & $49.01 \pm 0.05$ & 98.02 & 0.105 & 500 & $500.9 \pm 1.85$ & 100.1 & 0.36 \\
\hline
\end{tabular}

${ }^{*}$ Number of replications $=3$

\begin{tabular}{|c|c|c|c|c|}
\hline \multirow[b]{2}{*}{ Stress Conditions } & \multicolumn{2}{|c|}{ Canagliflozin } & \multicolumn{2}{|c|}{ Metformin } \\
\hline & $\%$ Drug recovered & $\%$ Drug decomposed & $\begin{array}{l}\% \text { Drug } \\
\text { recovered }\end{array}$ & $\%$ Drug decomposed \\
\hline Controlled sample & 98.02 & - & 100.1 & - \\
\hline Acidic $\left(0.5 \mathrm{~N} \mathrm{HCl}, 60^{\circ} \mathrm{C}, 60 \mathrm{~min}\right)$ & 93.6 & 4.4 & 96 & 4.1 \\
\hline Alkali $\left(0.5 \mathrm{~N} \mathrm{NaOH}, 60^{\circ} \mathrm{C}, 60 \mathrm{~min}\right)$ & 82.7 & 15.3 & 81.4 & 18.7 \\
\hline Neutral $\left(\mathrm{H}_{2} \mathrm{O}, 60^{\circ} \mathrm{C}, 60 \mathrm{~min}\right)$ & 94.8 & 3.2 & 97.3 & 2.8 \\
\hline Oxidative $\left(6 \% \mathrm{v} / \mathrm{v} \mathrm{H}_{2} \mathrm{O}_{2}\right)$ & 80.4 & 17.6 & 94.6 & 5.5 \\
\hline UV light (48 hrs) & 75.5 & 22.5 & 95.8 & 4.3 \\
\hline Thermal $\left(105^{\circ} \mathrm{C}, 48 \mathrm{~h}\right)$ & 95.3 & 2.7 & 98.9 & 1.2 \\
\hline
\end{tabular}




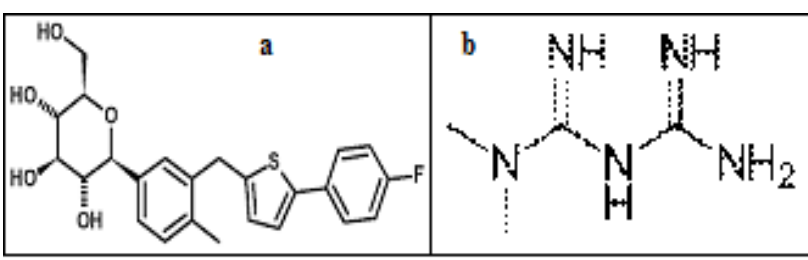

Figure 1: Chemical structure of canagliflozin (a) metformin (b).

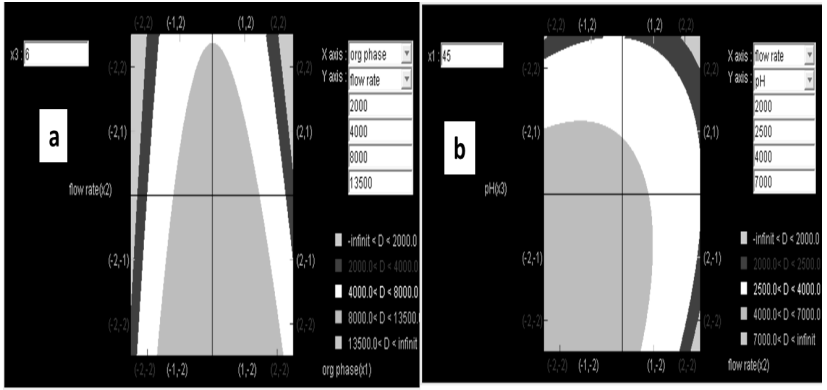

Figure 2: Contour plots for response-Theoretical plate count (Y) for canagliflozin (a) and metformin (b).

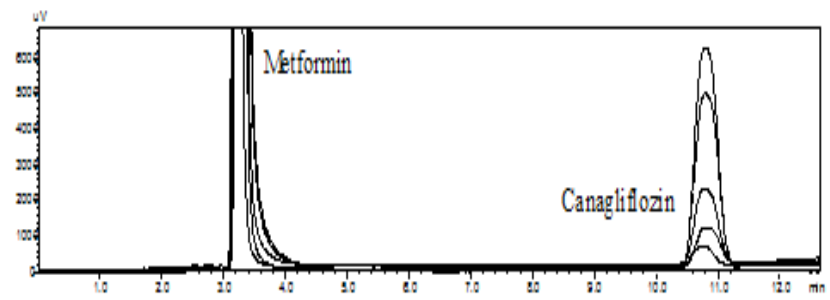

Figure 3: Chromatogram of linearity study.

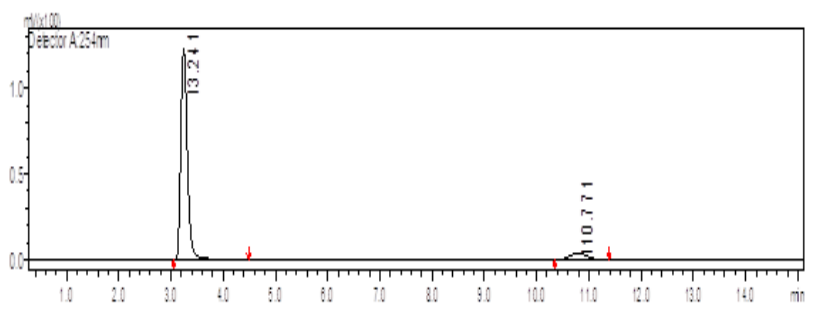

Figure 4: Assay chromatogram of canagliflozin and metformin.
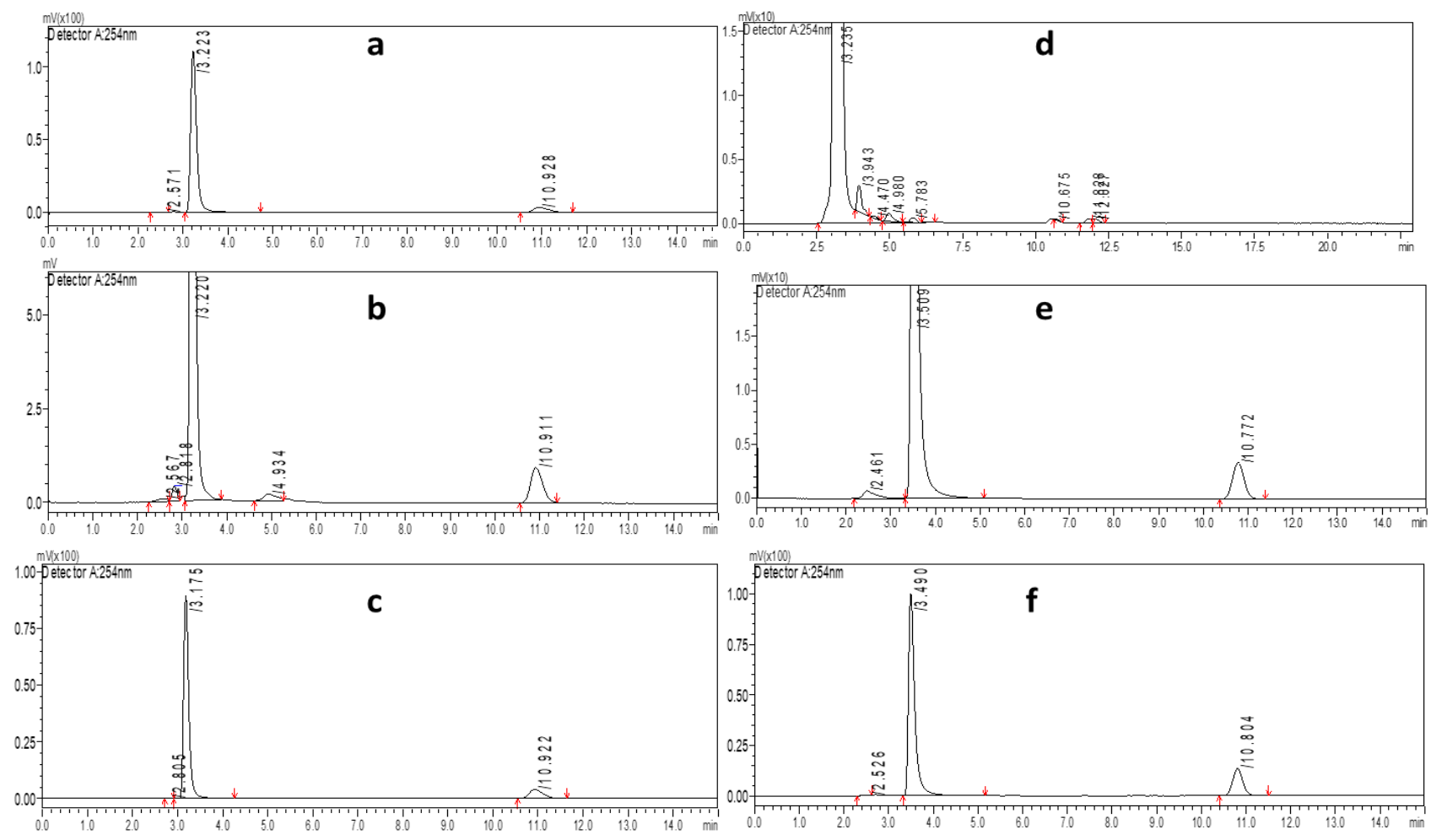

Figure 5: Chromatograms of stability studies under acidic (a), alkali (b), neutral (c), oxidative (d), UV-light (e) and thermal (f) Conditions.

and oxidation condition. Stress degradation study results of both drugs revealed its stability under thermal, acidic and neutral hydrolysis condition.

\section{Bioanalysis}

Recovery of drugs from biological sample was evaluated by comparing the chromatographic mean peak area with standard solution. The $\%$ recovery of canagliflozin and metformin from spiked human plasma was found to be $99.2 \%$ and $99.7 \%$, respectively. The chromatogram obtained through bioanalysis of title analytes has dearth of additional peaks, indicated no interference of biological matrix. 


\section{CONCLUSION}

A comprehensive analytical approach for simultaneous quantification of canagliflozin and metformin was depicted in this article. The experiments were conducted based on plan by central composite design in sigmatech software, which could save time, reagents and other resources. In this strategy, various constraints related to efficient separation of both analytes were considered and method parameters were optimized as $45 \%$ organic mobile phase (X1) at a flow rate of $0.8 \mathrm{~mL} / \mathrm{min}(\mathrm{X} 2)$ and aqueous phase $\mathrm{pH}$ at 6.0 (X3). These conditions were concluded as they show maximum response ( $\mathrm{Y} 1$ and Y2) and would bounce more economic method. The method was validated as per ICH guidelines. The prediction from MODR has been verified by concrete experimental results signifying its robustness hence suitable for method transfer and regulatory flexibility. The capacity of a method to distinguish and quantify canagliflozin/ metformin unequivocally in the presence of pharmaceutical excipient / biological matrix interferences was evinced. Forced degradation studies were performed on canagliflozin and metformin to prove stability-indicating a property of the method.

\section{ACKNOWLEDGEMENT}

The authors are thankful to Dr K Bhadraya, Director, Swaroop Tech Services Pvt Ltd., Hyderabad for supporting this work.

\section{CONFLICT OF INTEREST}

The authors declare no conflict of interest.

\section{ABBREVIATIONS}

AQbD: Analytical quality by design; HPLC: High performance liquid chromatography; MODR: Method operable design region; ICH: International Conference on harmonization; RSD: Relative standard deviation.

\section{REFERENCES}

1. Inzucchi SE, Bergenstal RM, Buseetal JB. Management of hyperglycemia in type 2 diabetes-A patient-centered approach. Diabetes Care. 2012;38(6):1409.

2. Ishpreet K, Sharad W, Harsharan PS. Development and validation of UV spectroscopic method for determination of canagliflozin in bulk and pharmaceutical dosage form. Pharm Methods. 2015;6(2):82-6.

3. Mohammad TIB, Farjana UK, Chironjit KS. Quality-By-Design approach to stability indicating RP-HPLC analytical method development for estimation of canagliflozin API and its validation. Pharm Methods. 2017;8(2):92-101.

4. Dudhe PB, Kamble MC. RP-HPLC method development and validation for the determination of canagliflozin in human plasma. Int $\mathrm{J}$ Pharmtech Res. 2016;9:174-81.
5. Ishpreet K, Sharad W, Harsharan PS. Development and validation of a stability-indicating High-performance Thin Layer Chromatography (HPTLC) method for estimation of canagliflozin in bulk and pharmaceutical dosage form. J App Pharm Sci. 2016;6(05):51-7.

6. Muzaffar I, Essam E, Khalid AA, Yousif AA, Naser LR. Rapid determination of canagliflozin in rat plasma by UHPLC-MS/MS using negative ionization mode to avoid adductions formation. Talanta. 2015;132:29-36.

7. Mubeen G, Khalikha N. Spectrophotometric method for analysis of metformin hydrochloride. Indian J Pharm Sci. 2009;71(1):100-2.

8. Mousumi K, Choudhury PK. HPLC method for estimation of metformin hydrochloride in formulated microspheres and tablet dosage form. Indian J Pharm Sci. 2009;71(3):318-20.

9. Madhukar, Prince A, Vijay KR, Sanjeeva Y, Jagadeeshwar K, Raghu PD. Simple and sensitive analytical method development and validation of metformin hydrochloride by RP-HPLC. Int J Pharm Pharm Sci. 2011;3(3):11720.

10. Himal PC, Panna T, Schepdael AV. Simple HPLC-UV method for the quantification of metformin in human plasma with one step protein precipitation. Saudi Pharm J. 2014;22(5):483-7.

11. Narasimha RD, Chandana M. Method development and validation of RP-HPLC method for simultaneous analysis of three-component tablet formulation containing metformin hydrochloride, pioglitazone hydrochloride and glibenclamide. Int J Pharm Tech Research. 2012;4(3):948-56.

12. Neelima K, Prasad YR. Analytical method development and validation of metformin, voglibose, glimepiride in bulk and combined tablet dosage. Pharm Methods. 2014;5(1):27-33.

13. Ayoub BM, Abdel-Aziz O. A guide for using experimental design in chromatographic method development: Applied to the analysis of selected anti-diabetic pharmaceutical combinations. Die Pharmazie. 2016;71(12):68390.

14. Rutvik HP, Rajeshwari R, Dilip GM. Bioanalytical method development and validation for simultaneous determination of linagliptin and metformin drugs in human plasma by RP-HPLC method. Pharmacophore. 2014;5(2):202-18.

15. Mowaka S, Mohamed D. Novel contribution to the simultaneous analysis of certain hypoglycemic drugs in the presence of their impurities and degradation products utilizing UPLCMS/MS. RSC Adv. 2015;5(74):60467-81.

16. Nidhi $K$, Jayvadan P. Development and validation of $Q$-absorbance ratio UV-spectrophotometric method for simultaneous estimation of canagliflozin and metformin in bulk and combined dosage form. Indo Am J Pharm Res. 2018;8:447-55.

17. Wafaa $A Z$, Shereen M, Moataz SH. Comparative liquid chromatographic study for concurrent determination of canagliflozin and metformin in combined tablets. J Anal Methods Chem. 2017;9197230. [cited on 2018 Oct 8]. Available from: https://doi.org/10.1155/2017/9197230.

18. Nareddy PR, Naga TC. RP-HPLC method development and validation for the simultaneous estimation of metformin and canagliflozin in tablet dosage form. Int J Pharm Sci. 2015;5(4):1155-99.

19. Uttam PP, Sunil KR. A Novel Validated RP-HPLC-DAD method for the simultaneous estimation of metformin hydrochloride and canagliflozin in bulk and pharmaceutical tablet dosage form with forced degradation studies. Orient J Chem. 2015;31(3):1489-507.

20. Deepak G, Patil RN, Mangesh H. A validated stability indicating RP-HPLC method for simultaneous determination of metformin and canagliflozin in pharmaceutical formulation. World J Pharm Pharm Sci. 2015;4:631-40.

21. Sonia DS, Krishna M, Sushmitha SG, Vasantharaju SG. Stability indicating assay method development and validation to simultaneously estimate metformin hydrochloride and canagliflozin by RP-HPLC. Curr Trends Biotechnol Pharm. 2016;10(4):334-42.

22. Vinutha K, Chowdary KPR, Prasad SVUM. Development and validation of a new RP-HPLC method for simultaneous estimation of metformin hydrochloride and canagliflozin and its comparison with the reported methods. World J Pharm Pharm Sci. 2017;6(3):696-713.

23. Parag D, Animesh M. Analytical Quality by Design (AQbD): A new horizon for robust analytics in pharmaceutical process and automation. Int $\mathrm{J}$ pharm. 2017;5:324-37.

24. Devesh AB, Smita IR. QbD approach to analytical RP-HPLC method development and its validation. Int J Pharm Pharm Sci. 2011;3(1):179-87. 
( Sanju N. Analytical quality by design (AQbD): New paradigm for analytical method development. Int J Dev Res. 2015;5(2):3589-99.

26. Peraman R, Bhadraya K, Padmanabha RY, Surayaprakash RC, Lokesh T. Analytical Quality by Design approach in RP-HPLC method development for the assay of etofenamate in dosage forms. Indian $\mathrm{J}$ Pharm Sci. 2015;77(6):751-7

27. Kim HBA. Hand book of stability testing in pharmaceutical development Springer International Publishing, Switzerland. 2009;146-8. Method Validation-A Review. Austin J Anal Pharm Chem. 2015;2(5):1053.

29. ICH Q2 (R1) Validation of analytical procedure: methodology. IFPMA. In proceedings of the International Conference on Harmonization, Geneva. 1996

30. ICH Q1A Stability testing of new drug substances and products. IFPMA. In proceedings of the International Conference on Harmonization, Geneva. 1996
PICTORIAL ABSTRACT

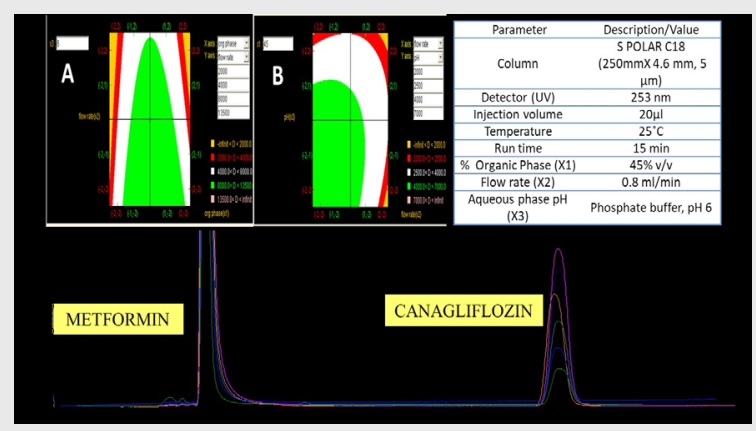

About Authors

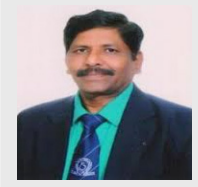

Prof. Shivaraj: Currently the Principal, University College of Science, Osmania University. He has 30 years of teaching experience in the Osmania University and as a Professor 11 years. He has guided 11 students for their Ph. D. degree. He Published 71 research articles in various national and international journals. He received 4 research projects worth Rs.66.00 Lakhs. He has organized three conferences in the department of Chemistry, Osmania University and presented 30 papers in national and international conferences. $\mathrm{He}$ is an Executive member of Indian Council of Chemists (ICC) from 2011. He has delivered 15 invited lectures in national and international conferences.

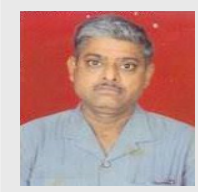

Prof. CVS Subrahmanyam, Principal, Gokaraju Rangaraju College of Pharmacy, Hyderabad. He has guided $17 \mathrm{Ph}$. D and 40 PG students for their research dissertation. He has 15 books to his credit. He has published 35 research articles in national and international journals and served as principal investigator for 4 research projects, funded by AICTE. He has presented 21 research papers and delivered 32 invited lectures in various national and international conferences/ seminars.

\section{SUMMARY}

The present HPLC study was time-honored with accurate and selective quantification of selected drugs in binary fixed dosage form without prior extraction. The experiments were conducted based on plan by central composite design in sigmatech software, which could save time, reagents and other resources. Analytical quality by design (AQbD) approach is one of the alternatives which dwindle the experimental time and cost for drug analysis. Use of experimental design in AQbD to optimize the robust chromatographic conditions, possess several advantages such as, provides an information about significance method parameters and their interaction effects to the method performance also provides scientific understanding to construct method operable design region (MODR), which signifies its robustness. This type of approach is recommended in future $\mathrm{QbD}$ based analytical methods as per FDA and ICH guidelines to attain regulatory flexibility and to avoid / minimize revalidation procedure during method transfer as well in change of method parameters. The capacity of a method to distinguish and quantify canagliflozin/ metformin unequivocally in the presence of pharmaceutical excipient / biological matrix interferences was evinced. Forced degradation studies were performed on canagliflozin and metformin to prove stability-indicating a property of the method. Stability study through forced degradation of drug was used to predict the instability of drug and provide knowledge about possible degradation pathways, degradation products of the active ingredients also helps to elucidate the structure of the degradants through characterization. Hence, it can be effectively applied for the routine analysis in research institution, quality control department in industries, approved testing laboratories, biopharmaceutical studies and clinical pharmacokinetic studies for simultaneous determination of canagliflozin and metformin. 


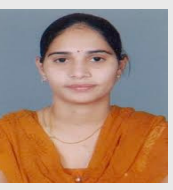

Sunitha Gurrala is an Assistant Professor in the Department of Pharmaceutical Analysis, Gokaraju Rangaraju College of Pharmacy. She has 7 years of teaching experience and has published 22 research articles in reputed journals. She has published 5 conference papers and guided 21 PG students for their research dissertation.

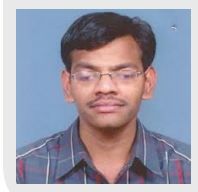

Dr. Panikumar Durga Anumolu, Working as Associate Professor, Gokaraju Rangaraju College of Pharmacy. He has 12 years of teaching and research experience. He has published 42 papers in national and international journals. He has attended 12 conferences, presented 7 papers. He has guided 27 PG students and served as principal coordinator for SG, sponsored by AICTE.

Cite this article: Gurrala S, Shivaraj, Subrahmanyam CVS, Panikumar AD, Gowthami S. Analytical Quality by Design Assisted HPLC Method for Quantification of Canagliflozin/ Metformin and Stability Studies. Indian J of Pharmaceutical Education and Research. 2019;53(4s):s699-s709. 